\title{
O NEOHUMANISMO DA NON CIDADE
}

Félix Duque

Universidad Autónoma de Madrid 

En realidade, xa hai tempo que sabiamos da existencia dun ilustre cadáver colgado, ás veces de maneira vergoñenta e case ás agachadas, en calquera pendón dos defensores a morte dos Tempos Modernos: o cadáver do humanismo, ás veces bautizado, e nunca mellor dito, como «humanismo cristián». Só que estes restos inanes xa non asustan a ninguén, nin tampouco -vistos polo outro lado-infunden moitas esperanzas de restauración dos good old times. É lóxico. Un cadáver non é unha pantasma. Non é un revenant. Certamente séguese obrigándoo a volver, a tombos; pero faino como o que é, ou mellor como algo que está «de corpo presente»; así que son moi poucos os que o toman en serio, agás como «chibolete», segundo a castiza tradución de Miguel de Unamuno para o hebreo shibboleth, ou sexa, coma unha consigna, unha chiscadela para facernos ver que o protagonista do faladoiro do caso é «dos de toda a vida» ou, pola contra, un tipo pouco de fiar. De feito, os empeñados en resucitar tan rancio morto preguntan, finxindo escandalizarse: «Pero, home! Que pode haber desde logo máis sagrado para o home que o propio home?». Así que, interpelado por tan contundente pregunta, un vese forzado a descender de novo á area para bosquexar unha breve recapitulación dos trazos xerais do humanismo; uns trazos ben contraditorios, ao meu ver (Duque, 2003).

Todo humanismo que se teña por tal depende dunha proposición en aparencia tan evidente que resulta máis ben tautolóxica, a saber: "Cada home é o Home». O humanista seareiro aquí case teratoloxicamente é o predicado esencial Home, mentres que, por outra parte, pretende menosprezar o suxeito realmente existente, o home que é cada un de nós, cada quisque, incluído eu mesmo.

$\mathrm{Da}$ abstracta entidade primeira fálanse marabillas, todas elas presididas ou precedidas polo prefixo auto-, ser un mesmo. En efecto, o Home sería un ser autónomo, autocentrado, autosuficiente, autárquico, cando menos a través dos seus representantes, por el libremente elixidos, faltaría máis!, e ultimamente, por mor da enxeñaría xenética, ata autooperable, que sempre queda máis fino que automanipulable (Duque, 2002). 
Ao caer tan rotundo ideal sobre cada quisque, faise deste un suxeito de (ou alguén suxeito a) imputabilidade, moral e penal, absolutamente responsable de actos propios, conscientes e voluntarios, co que se converte ademais e sobre todo a cada portador ou soporte da entidade Home nun ser persoal e inalienable de valor absoluto: algo por certo que xa debería facer que sospeitásemos, dada a súa semellanza co documento nacional de identidade, tamén designado pola autoridade competente como "persoal e intransferible». Así, o Home sería, redundantemente, o Ideal da Humanidade, o baremo co que un se ten que medir para ver canto dá de si, é dicir, canto dá cada un de si, segundo o caso e a circunstancia, a prol dese excelso e inabarcable Si mesmo.

Só que polo lado do suxeito, do ego homuncio do caso, tan estupenda identificación ad limitem non semella desde logo posible, non sendo que, como resultaría dunha lectura malévola da Declaración dos Dereitos Humanos da ONU de 1948, ese suxeito fose en última instancia un presque rien, case nada, a saber, alguén a quen hai que respectar e defender, pero, quen o faría?, acaso os demais «alguén», en xeral?, con independencia da raza, credo, linguaxe e demais características particulares. Ou sexa, que habería que respectar un resto inane, o resultado de eliminar dun ser - de calquera- toda particularidade. A non ser que, nunha lectura bondadosa, entendamos que cómpre respectar e defender ese «algo» que está en «un» e que o marca; é dicir, respectar a todo o mundo non malia súas particularidades, senón precisamente por elas. Pero daquela, desde onde habería que exercer o respecto?, talvez desde outro cúmulo de particularidades? E como unhas particularidades, por centradas que estean en alguén, poden respectar outras propias de e existentes noutro alguén, non sendo que exista un fundamento común que as faga compatibles? Como podo ser representante da Humanidade na miña persoa, que dicía o bo Kant, sen selo desde unha base que, atravesando toda a lira da evolución mineral, vexetal e animal no meu corpo, continúa pola familia, a sociedade civil, o Estado e ata a adscrición a un club de fútbol? Acaso será o Concepto-Home a omnitudo negationum, a totalidade resultante de negar todas esas determinacións? $\mathrm{E}$ iso é o que o Humanismo quere que eu sexa, precisamente eu mesmo?

Por outra banda, esa operación de subtracción, de despoxo, continúa e agrávase cando, das alturas dos Dereitos do Home en xeral, descendemos aos detalles en que e polos que viven os homes. Por exemplo, cando chegan as eleccións, un 
querería matizar, explicar xustamente con detalle por que vota a tal político e non a outro, pero as papeletas xa están preparadas cuns nomes predeterminados, que obedecen a intereses que en boa medida ignoro, fortalecidos -nomes e intereses- polos medios de comunicación de masas, etc. Ao cabo, eu non son máis que iso: un home, un voto. E no plano económico, non son, non somos, outra cousa que man de obra, forza de traballo intercambiable no mercado libre e globalizado. Así que, finalmente, e sobre todo nos casos extremos, o xuízo: "Cada home -este, esoutro ou aquel- é o Home -en xeral, sen entrar en detalles-» é, segundo se mire, asemade tautolóxico e contraditorio. Tautolóxico, porque por ambos os dous lados -o do predicado e mais o do suxeitodepuráronse tanto os diversos modos e maneiras de ser home que, ao cabo, non quedan máis ca restos, por un lado, e xeneralidades, por outro lado; a saber, algo así como que "a existencia, cuantitativamente tomada, dun en un, é o mesmo que a esencia tomada colectivamente, en xeral». E ese "o mesmo» é, no fondo, nada. Así que o humanismo desemboca no nihilismo, deixando, iso si, uns restos, os únicos que nos interesan, os que nos fan ser, a cada un, un mesmo, á súa maneira. Xa o advertín antes: tratábase dun cadáver inane e descarnado, sen chegar ao plano espectral. Pero ese xuízo é tamén contraditorio, se o consideramos desde o punto de vista da lóxica clásica, quer de subsunción, quer de inhesión. Desde o primeiro, é evidente que non podemos subsumir directamente un singular, ou unha chea deles, para o caso dá igual, baixo un concepto universal, o de Home, neste caso. Para poder facelo, o suxeito debería mostrar no seu concepto algunhas notas particulares, específicas, e xa que logo compatibles co concepto do predicado. Agora ben, agás a repetición salmódica de que o home é un animal racional $-o$ que volve resultar un ferro de madeira-, xa vimos que o humanista ten que negarse a aceptar particularidades que relativizarían o augusto concepto do Home. Pero desde a lóxica de inhesión é peor, xa que ao incidir tan tremendo e vacuo concepto sobre cada un de nós procede aquel necesariamente a unha depuración moito máis drástica que a étnica -aínda que, por fortuna, e ata o de agora, sexa só simbólica- para poder adecuar a súa vacuidade a un suxeito igualmente baleirado e oco.

Así e todo, o feito de que tan fácil vitoria sobre o humanismo non impida que nos máis variados lugares e desde as máis diferentes bocas e caletres se continúe a defender desatino semellante como algo evidente e ata de bo ton, ese 
feito, digo, tería que levarnos a pensar que talvez esa universal defensa, ligada as máis das veces a desexos imperiosos, e mesmo impetuosos, de acceder a un benaventurado cosmopolitismo, agache, sabéndoo ou non, unha clara toma de postura ideolóxica, a saber: a crenza de que certas persoas, grupos ou Estados nacionais dominantes, quer por dereito teolóxico -agora lévase outra vez iso-, quer histórico, tecnocientífico, ou simple e cinicamente fáctico -á forza e pola forza... das armas-, de que eses grupos son a encarnación, a proba vivente aquí, na terra, desa humanidade á que tantos outros aínda non chegaron, e aos que cómpre axudar a iso, polas boas ou polas malas. E se as malas o son tanto que pareza que non hai remedio para reintegrar os díscolos na grea humana, daquela haberá que aniquilar eses estraños homes que se negan a selo, é dicir, que se negan a ser coma nós, coma o nós que dita e decide o que significa ser de verdade home, e que nación encarna mellor a existencia dese concepto, a forza de igualdade, unha vez trituradas as diferenzas, ou utilizadas como material de elaboración e consumo; de liberdade, unha vez aceptada a orde establecida e as súas regras do xogo; e de fraternidade, é dicir, do intercambio de bens entre os irmáns dependentes do mercado global.

Así pois, ben mirado, para que a doutrina do humanismo sexa posible cómpre atopar un analogatum princeps, unha distinguida particularidade a través da que cada individuo poida ser transmitido, transferido a esa universalidade chamada Home. Antes falábase do espírito dun pobo que, en cada época, se convertía en portavoz e soporte do espírito do mundo; logo tocou falar dunha raza superior ou, á inversa, do socialismo nun so país; e agora, por fin, «vencido y desarmado el Ejército Rojo», por Coca Cola e Cía.!, temos o flamante imperio democrático, outro bonito paradoxo, como paradigma, ou mellor, como pattern do que debe ser o Home, xunto co segregado polo imperio mesmo como as súas feces, espalladas despois polo mundo atopando o fecundo humus do fanatismo, e reunidas indistintamente baixo a sinistra denominación de terrorismo internacional, o lado escuro da forza, tan universalmente abstracto como o seu lado bo. Segundo isto, na proposición universal que vimos de examinar sobre o Home son evidentes, de súpeto, así mesmo, o seu carácter ideolóxico e o seu sentido loxicamente condicional: «Si pero só cando este home é norteamericano, daquela é todo un home». 
Isto implica a cláusula negativa: «Todo home que odie ou que se enfronte aos norteamericanos non é realmente un home, é un terrorista». Entremedias de tan extremas proposicións movémonos, somos e existimos os demais: os que non formamos parte dos elixidos, pero facemos o posible por irnos acercando, e os que, malia non seren totalmente réprobos, non protestan o suficiente contra eses tales.

Gustaríame chamarlle neohumanismo á doutrina que propugna o seguinte donoso siloxismo: "Este home -singular: E- é home -universal: A- por ser norteamericano ou afín -particular: B-». É dicir, E-B - A. Non dixera Hegel que América era o país do porvir? $\mathrm{E}$ onde atopar esa renovada doutrina de veneración do home polo home? Atoparémola, dunha maneira tan obvia como redundante e recorrente, na WorldWideWeb, baixo o rótulo: Humanism. Trátase do credo da moi poderosa American Humanist Association, que, por boca do seu presidente, Federick Edwords, nos adoutrina deste xeito: «O humanismo é unha desas filosofías para a xente que pensa por si mesma». Ben está.

Quen non aceptaría que el ou ela pensa por si mesmo ou mesma? Claro que xa esta dobre formulación, vinculada ao politicamente correcto, nos fai ver, para empezar, que baixo o paraugas xeral, de novo, a trampa dos nomes comúns, da xente, do people, existe xa unha diferenza irredutible: a sexualidade, que talvez teña algo que ver con iso de pensar por conta propia e, así e todo, non poder estar de acordo, agás en xeral. É que iso de pensar por conta propia, de clara e nobre ascendencia kantiana, esquece que foi o propio Kant o que esixiu, así mesmo, que para iso era preciso poñerse no lugar do outro, e que só así cabía pensar dunha maneira consecuente. Como se ve por ese esquecemento da radical alteridade, a máquina uniformizadora do neohumanismo xa comezou a funcionar. Non se deterá. Vexamos:

«Humanism is a philosophy focused upon human means for comprehending reality. Humanists is a philosophy of reason and science in the pursuit of knowledge [...]. Therefore, when it comes to the question of the most valid means for acquiring knowledge of the world, Humanists reject arbitrary faith, authority, revelation, and altered states of consciousness». Imos por partes:

"O humanismo é unha filosofía que para a comprensión da realidade se centra nos medios humanos». A idea de que o home ten ao seu dispor medios implica eo ipso que o Home é un obxectivo en si mesmo. Isto remítenos de novo 
a Kant, só que coa non pequena excepción de que Kant erixía o home como «fin final» da natureza... no ámbito moral, non no cognoscitivo, dado que neste vía o home como dobremente suxeito a un aparato transcendental, cuxa orixe e sentido na moralidade ignoraba, e á doazón do material da sensación por parte da experiencia. Por iso insistía en que el, Kant, debera relevar (aufheben) o saber, rebaixando as súas pretensións de «sabichón», para deixarlle sitio á crenza, por racionalmente motivada que esta fose.

Pola contra, o neohumanismo defínese como unha filosofía da razón e a ciencia na procura do coñecemento. Por certo, se Edwords está xa seguro do poder da razón e a ciencia nese plano, non se ve a necesidade de mencionar a filosofía, agás que, aquí, o termo signifique xustamente convicción ou crenza. A saber: Edwords, portavoz e portador da razón, pensa que a razón é o mellor para coñecer algo, dado que ela vén implicitamente definida como o medio humano de coñecer algo. Como se ve, todo isto é moi filosófico, e moi edificante, porque a continuación se nos revela contra quen se dicía isto, rebelándose contra eles: «os humanistas rexeitan a fe arbitraria, a autoridade, a revelación e os estados alterados de conciencia». Repárese nos termos do rexeitamento: obviamente, este vai dirixido contra os fundamentalistas relixiosos que son antihumanistas -imposible non pensar aquí nos fanáticos islamistas-, así como contra a New Age e as súas secuelas, co seu escurantismo e o seu consumo indiscriminado de drogas, cousas ben insás -e certamente o son; só que non se fai mención ningunha doutras posibilidades de alteración de estados de conciencia. Naturalmente, queda fóra de toda condena a fe non arbitraria, por exemplo, a propia da confesión metodista do aínda presidente Bush. Pola contra, por mor desta fe sostén no fondo o siloxismo neohumanista, tan redundante e circular como o soportado por el, e que xa coñecemos: «Este home -se é tal home distinguido- é o Home». Pero agora, a circularidade, convertida en fundamentum inconcussum veritatis, dáse no pobo elixido de Deus; un pobo que, pola súa vez, elixe libremente, por suposto, esa opción, ou sexa, que elixe o Deus que o elixe a el: In God we trust, ou o que é exactamente a mesma cousa: God bless America. Á confianza correspóndelle biunivocamente a bendición, e viceversa. E se a ese entrecruzamento de boas intencións lle chamamos vida, así, en xeral, xa temos a definición esencial do noso neohumanismo: «Humanism is, in sum, a philosophy for those in love with life». 
Isto de namorarse da vida por parte dun ser vivente resulta algo tan inxenuamente obvio -non é preciso ser spinozista para entender que todo ser vivente queira seguir vivindo-, tan circularmente banal como o referente oculto tras o termo vida, a saber, o Home. Próbese a cambiar esta palabra e a suposta definición rezaría así: "O humanismo é en suma unha filosofía daqueles -hombresque están namorados da vida humana». Non penso que a vida das células canceríxenas lle apaixone en absoluto ao noso flamante neohumanista. Así que o neohumanista se move tan circularmente como o paleohumanista moderno. Pero o primeiro atopou para os seus asertos unha base máis sólida que a Asemblea de Nacións Unidas: asentouno, en efecto, na pedra granítica de The Big Country, abarcada e bendicida desde arriba, uno intuitu, pola aguia divina.

A que se debe tan fundamental privilexio? Escoitemos agora outra voz; esta vez máis aguerrida, sen complexos. É a de Niall Ferguson, co seu Colossus (Ferguson, 2004). O Coloso -de buscadas resonancias romanas- é naturalmente o imperio americano: o sucesor, segundo Ferguson, do case fenecido imperio británico, que pola súa vez tomara o relevo das ruínas do imperio romano, tan minuciosamente narradas por Edward Gibbon ata a caída de Bizancio en 1453, co pouco disimulado obxectivo de conectar tamén temporalmente coa grandeur de Roma, que diría Poe.

Para Ferguson, os Estados Unidos de América constitúen un «imperio liberal que sustenta regras e institucións e asegura o ben público a base de manter a paz, de garantir a liberdade dos mares e os ceos e de xestionar un sistema internacional de comercio e finanzas». Neste sentido non se distinguiría demasiado dos seus ilustres predecesores, se non fose porque a sociedade civil na que se asenta ese imperio é «aberta e integradora» -manes de Popper!-, e tamén «inclinada a gobernar de maneira informal. Ao respecto, Ferguson cita con admiración -un tras outro, sen ter en conta as diferenzas-a Woodrow Wilson, Franklin Roosevelt, John F. Kennedy, Ronald Reagan, Bill Clinton e George W. Bush, porque todos eles puxeron o enorme potencial americano ao servizo da promoción dos "grandes ideais liberais de apertura económica, democracia, goberno restrinxido, dignidade humana e o imperio da lei». Todo iso pódese resumir en catro palabras: a strategy of openness; unha estratexia de apertura. Pode supoñerse que é a apertura dunhas fauces que tragan mercados e sistemas políticos, mais con tanta xenerosidade que premian con Purple Hearts e coa cidadanía americana os 
soldados estranxeiros que combaten xunto aos americanos en Iraq, para que poidan dicir, coma en Roma os lexionarios: civis romanus sum, mentres que impregnan o globo da lingua, as ideas e a cultura imperiais. Como diría Gershwin: Who can ask for anything more?

Para aplicalo, renovado, ao proceder do garante do New World's Order, o apoloxista do Coloso non ten reparo en sacar a relucir ao respecto o nobre credo do imperialismo británico propalado por Winston Churchill: «Pacificar tribos guerreiras, administrar xustiza alí onde todo era violencia, romper as cadeas do escravo, extraer riquezas do chan, esparexer as primeiras sementes do comercio e da aprendizaxe, incrementar en pobos enteiros as súas capacidades para o pracer, diminuíndo as ocasións de dolor». Así pois: ao humanismo polo imperialismo! Ao cabo, non fora o propio Kant o que dixera que, en canto membro dunha especie, o home é un animal que precisa dun amo? E que mellor que un amo que, tomando o relevo da madrasta natureza en Kant, fai o imposible por favorecer os seus protexidos e trata de conseguir que eles xa non o necesiten ningún día, igual que os colonos norteamericanos deixaron de precisar en 1776 a benéfica atención dos amos británicos?

É máis: os Estados Unidos merecerían encabezar a cruzada mundial en favor do humanismo, xa que eles serían os primeiros en encarnar a nivel planetario a «insociable sociabilidad» que Kant fixara como esencia do home. En efecto, ao tratarse dun imperio democrático, América ten que esforzarse por afastar de si todo imperialismo -non pode darse un imperio imperialista!-, sen deixar, por outra parte, de utilizar o hard power onde e cando sexa preciso -non pode existir unha democracia inerme! América é sociable cos socii que se acomodan aos intereses do imperio -e, por este lado, é ela mesma, en si, insociable. Pero debe soster así mesmo os seus aliados e ceder en ocasións diante dos seus propios intereses inmediatos, a curto prazo -sendo, por este lado, pois, en si sociable con eles e insociable cos inimigos comúns.

Así que a inédita conxunción de seguridade, apertura, democracia, compromiso político e, last but non least, mobilización do poder americano de guerra abrirían o camiño que desembocará na soñada "Cosmópolis» mediante a conxunción das dúas forzas que tamén Kant propugnara en Cara á paz perpetua: a expansión económica mundial -globalización do libre comercio- e a integración paulatina de todos os Estados -agás os rogue States, naturalmente- no 
New Order liberal. Estamos así achegándonos á raíz mesma do neohumanismo. Para que esta fráxil flor logre crecer na actual orde internacional, di Ferguson, resulta absolutamente necesario establecer un duradeiro enlightened leadership, un liderado ilustrado -tamén Edwords fala dun humanismo in tune with today's enlightened social thought-, vinculando así pola forza «non á forza!» dous termos dispares, certamente, mais non disparatados - basta botarlle unha ollada ao que facían as sediciosas nacións ilustradas no século XVIII e no primeiro terzo do XIX. Desde logo, a vella Europa non estaría nin moito menos en condicións de asumir o imperium, sumida como se atopa nas súas contradicións internas, en pleno proceso de ampliación cara ao Leste -algo que resulta conveniente para os intereses americanos, se é que non se trata dunha suxestión, dunha recomendación ou dun mandato do imperio. Só o protectorado americano garante unha imperial supervision que impida o rexurdir no Terceiro Mundo dos sempiternos conflitos tribais - un rexurdir, por outra banda, que sería un signo da pouca maña que no seu día tiveron as potencias coloniais para cumprir o compasivo programa de Churchill. Pois -Ferguson incide en algo innegable-: «o experimento coa independencia política [das colonias], sobre todo en África, foi un desastre para os países máis pobres». Só que o noso apoloxista do Coloso semella aproveitar ese fracaso para volver poñer sobre o tapete a vella cuestión: para chegar algún día ao cosmopolitismo e á paz perpetua, que será máis posible para o espírito do mundo: ben unha «orde internacional organizada arredor das nacións independentes, establecendo regras multilaterais e asociacións - partnerships- estreitas", ou ben an American Imperium? Como podería esperarse -aínda que non sen sentir arrepíos-, Ferguson apoia decididamente esta última opción e ofrece como xustificación a indución seguinte, ben cuestionable polo demais: posto que o experimento das potencias coloniais europeas resultou un fracaso e un caos para o interior das antigas colonias, nin unhas -a vella Europa- nin as outras -sobre todo África, á que habería que abandonar á súa sorte e deixala por imposible- poderían participar no xogo mundial dunha Federación de Nacións Libres como a defendida por Kant en 1795. Escoitemos como pontifica Ferguson: «un mundo de Estados descentralizados e competitivos, moitos dos cales non son democracias, desembocaría no caos». Xa que logo, e como dicía xa Aristóteles ao concluír o libro XII da Metafísica -alí onde, non en van, se fala de Deus-: «Non é bo o goberno de moitos: que haxa un único Señor». 
Agora ben, non por iso ten que volver tampouco o noso colosal adaíl á outra opción: a Weltrepublik, como propugnara igualmente Kant en 1784 e logo en 1798, despois de que pasara o interregno do terror, que o levara, prudente, a buscar triste consolo nun Foedus Amphyctionum. O sedicioso imperio democrático actual gobernaría certamente o mundo, pero a distancia, deixando que só os cidadáns dos Estados Unidos -e os soldados estranxeiros superviventes que o merezan, diriamos pola nosa conta- gocen das vantaxes de ser dese país, e empregando a forza só nos casos extremos, debendo utilizar en cambio, máis ben, do soft power que lle outorga a súa cultura superior, desexada como un polo de desenvolvemento por todos os demais países -é sabido que esta é tamén a tese moderada, se a comparamos co intervencionismo militar, de Joseph S. Nye: os Estados Unidos non necesitan usar a forza; bástalles con ofrecer a american way of life a través dos canais mediáticos e a venda de películas e gadgets: desde a CNN ao imperio Disney. Liberal hegemony: tal é a fórmula en que se condensan os exhortos ad intra da American Humanist Association e as pouco veladas advertencias ad extra de Colossus.

Se quixésemos ilustrar historicamente a tese antes probada loxicamente, a imposibilidade de enlazar o singular «este home» co universal «Home», poderiamos remitirnos a dúas voces antigas. Respectivamente, a de Protágoras, para quen cada home é a medida, e dá a medida, de todas as cousas -das que son, en canto que son; e das que non son, en canto que non son-, facendo así que a multiforme realidade se dobregue, dócil e predisposta, so sic volo sic jubeo de cada quisque -individualismo, pois-; e a de Terencio, co seu apotegma, tantas veces citado como summa do humanismo: Homo sum: humani nibil a me alienum puto, é dicir: toda realidade é, no fondo, humana. E, xa que logo, é, no fondo tautolóxico, o que nada -nada humano- lle sexa alleo ao home que é, que hai en min, ese Home que me fai ser o que son - universalismo. Pois ben, tamén historicamente -Fukuyama diría: ao final e como final da Historia Universal- os Estados Unidos -na interpretación de Ferguson, desde logo non illada- arrogarían a solución da contradición entre individualismo e universalismo. Pois só eles serían, por unha parte, un Estado Nacional Democrático, e por conseguinte un e indivisible: e pluribus unum -co que se satisfarían as esixencias do individualismo: o que é o Estado-individuo no plano internacional sono igualmente os cidadáns-individuos no plano nacional-, mentres que, por outra parte, non 
deixaría de ser América, indisolublemente, un imperio mundial, chamado a establecer a paz perpetua: o Reino de Deus sobre a Terra -co que se cumpre o requirido polo universalismo.

Polo menos a min non me parecen moi convincentes as razóns aducidas, en parte, suplementadas e perfeccionadas por min mesmo, seguindo o xeneroso consello de Hegel: a refutación do adversario só pode ser interna, facendo ver as contradicións que o moven; nin desde logo moi desexable ese formidable rebumbio de humanismo, imperialismo e democracia, sobre a base do capitalismo neoliberal, ao que se intenta que nos afagamos. A vinculación entre humanismo e imperio pode constatarse ao longo da historia: basta con pensar en Roma e na Inglaterra do Rule Britannia!; tampouco é nova a conexión entre humanismo e democracia: lémbrense a Grecia de Pericles e a Florencia dos Médicis; o inédito da situación actual é a dobre ancoraxe de imperio e democracia no fundamento do humanismo, como se deste modo se esgotasen as posibles maneiras de entender a gobernación humana.

Penso, pola contra, que existe outra opción, non en van rexeitada nerviosamente por Ferguson, sen argumentar practicamente as razóns. Por unha banda, atopámonos, en efecto, cunha poêle mêle de nacións en igualdade -algo que a ONU tampouco é-, sexan ou non democráticas polo que toca ao Dereito Civil ou Penal, obedezan ou non a principios mínimos do Dereito Internacional -principios que, polo demais, son os Estados Unidos os primeiros en non aceptar. Por outra banda, estamos asoballados por un imperio disque democrático, tendente a confundir pro domo os seus propios intereses cos intereses da poboación mundial e empeñado en democratizar mediante intervencións humanitarias a quen nin o desexa nin o entende.

Tertium non datur? Non o creo. Pois é posible que entre ambos os dous extremos se estea a abrir paso, moi traballosamente, é verdade, e con desacordos importantes, a opción exemplar dun pequeno grupo de Estados dispostos a ceder parte da súa soberanía e a intercambiar non só persoas e bens, senón tamén, e sobre todo, modos diversos de vivir e de pensar, de gozar e de sufrir. E isto, ata o punto de darse por común acordo, ratificado polos cidadáns dos diversos membros, unha Constitución non outorgada polo soberano -aquí non hai soberano- nin asinada contra un inimigo que se teña que excluír e vencer -os británicos no caso da Constitución americana, l'Ancien Régime no da Revolu- 
ción Francesa. Nin unha Federación mundial de pobos, pois, nin tampouco un imperio xeograficamente delimitado pero económica, telemática e militarmente disperso por toda a face da terra, senón simplemente unha unión de Estados, tendencialmente máis acordes no político e o económico canto máis fecundamente discordes naquilo que poñía nervioso ao bo Kant e que aínda lembra Ferguson, a sensu contrario, a saber: a pluralidade de linguas, de ideas e de culturas. Os cidadáns europeos - posto que da nova Europa estou a falar- non o son con independencia deses caracteres diferenciais, senón precisamente por eles.

Agora, a pregunta que naturalmente se impón é: ten esa concordia discors unha base humanista? É posible edificar unha Europa unida sobre a base do humanismo, quer moderno -xurdido, non se esqueza, ao mesmo tempo que os nacionalismos-imperialismos do XIX, talvez como un modo máis ou menos vergoñento de ocultar dun modo irenista a feroz competencia capitalista que levaría ás guerras mundiais-, quer o do imperio democrático? Desde logo, unha contestación contundente ao respecto sería tan excesiva como pouco convincente. E, así e todo, algo si se pode adiantar. Se Europa non renega da súa tripla raíz cultural e relixiosa (a grega, a xudía e mais a cristiá), resulta difícil pensar que se acolla algunha vez ao credo humanista. Pero, se algunha vez o fai, considero que daquela deixará de ser Europa, por máis que continúe a ter tan venerable nome. É máis, se a través primeiro de Turquía, e logo dalgunhas repúblicas balcánicas, tras a súa relativa pacificación, lle dá cabida Europa á herdanza -transformada e revisada- do antigo e pertinaz adversario (o islam, co seu Deus transcendente), reforzará aínda máis a tendencia contra o neohumanismo para salvar xustamente a dignidade do home e o seu posto no cosmos como mediador de rexións. En todas esas tradicións, en efecto, imponse unha dobre fronte, de raíz grega, contra o individualismo e o universalismo, os dous puntais que intenta identificar o humanismo.

Contra o primeiro, o individualismo, cómpre lembrar agora e sempre a rotunda afirmación de Heráclito: «É preciso obedecer ao que é común; non obstante, malia que o logos se dá en común, moitos viven como se tivesen unha intelixencia propia, particular (idian phrónesin)» (DK22B2). Unha sentenza que resoa moito despois en Platón, e que el guinda como un venabre contra o relativismo de Protágoras: "Deus, certamente, ha de ser a nosa medida de todas as cousas; e non, desde logo, o home, como adoitan dicir por aí» (Leis, 716 C 4). 
E contra o segundo, o esencialismo universalista, de novo nos advirte Heráclito: «Non atoparás nunca os límites da alma, aínda que atraveses todos os camiños; tan profundo é o seu logos» (DK22B45). Xamais o pensamento dun individuo chegará a ser igual ao logos, á razón que o sostén. Nunca as palabras esgotarán o sentido das cousas. Xamais poderemos facer outra cousa que sacar á luz a cerrazón mesma, a impenetrabilidade da Terra. Nunca estará na nosa man a medida, xa proveña esta de Deus, da Lei ou doutra instancia impersoal. Podemos ser tradutores e condutores, bos condutores, como bos europeos, do sentido último da verdade, pero non utilizala como medio en beneficio humano. Podemos estar na verdade, pero non dispoñer dela. Podemos axustarnos ao que é se, colaborando coas forzas naturais e as técnicas en continua transformación, perfeccionamos mediante o traballo e a acción, cousas e obras para facer que se abran como flores na interacción do home e do ser, no van en que ambos os dous se logran. Unha vella sabedoría agroma así na alma do novo europeo: harmonízanse as leis da terra (chthonòs) e a xustiza xurada dos deuses, exaltado sexa na cidade (hypsípolis); sen patria (ápolis) sexa quen, levado da insolencia, vive na inxustiza (Sófocles, Antígona, vv. 368-371).

A cidade dos mortais álzase, en efecto, nese intervalo entre terra e ceo, agardando os sinais propicios ou adversos do divino, lembrando que mesmo a Cruz é un Wegweiser, un indicador de camiños e un separador de rexións. Por iso procede preguntarse se as diverxencias sospeitadas entre os Estados Unidos e Europa respecto do sentido último da humanitas do home establecen igualmente diferenzas no modo de habitar a terra. E tamén neste ámbito da arquitectura e o urbanismo cabe albiscar -dentro das innegables semellanzas, produto dunha mesma civilización, a da absolutización da técnica- unha distinción fundamental, a saber: os americanos tenden a establecer dous sentidos antitéticos, extremados e extremosos, de edificación: dun lado, a dispersión en mancha de aceite (sprawl cities) para a habitación humana, con casas unifamiliares -illadas ou acaroadas- no medio da natureza, formando conurbacións; do outro, a concentración na chamada Downtown de grandes torres-rañaceos, unidas entre si por postigos aéreos ou por corredores subterráneos, como na Universidade de Minneapolis. E para unir ambos os dous conxuntos, redes e nódulos de autoestradas, físicas ou virtuais - as chamadas autoestradas da información: pura mobilidade entre a concentración e a dispersión. De aí que o tipo correspon- 
dente de cidade oscile entre a City of Bits e a Sim City, a cidade toda ela simulacro, como Orlando en California, co seu hábitat adxacente: Celebration, unha cidade de nova creación -aséptica e pasteurizada-, que é tamén un produto Disney, ou Las Vegas en Nevada.

Pola contra, as cidades europeas tenden a conservar, e moitas veces a inventar o que pensan que é digno de ser conservado, a superposición, xustaposición e, ás veces, a inexorable destrución das distintas vagas de estilos arquitectónicos, encaixados pola forza nunha tradición que, na meirande parte dos casos, resulta produto dunha reflexión calculada, dunha recreación da historia, para subliñar o fet diferencial -baste pensar, en efecto, en Barcelona, co seu falso Barrio Gótico e o vulgar sincretismo do Pueblo Español, ou no Barrio de Santa Cruz de Sevilla, por non falar de estereotipos restaurados e repintados ata convertelos en tarxeta postal, como no caso de Santillana del Mar, Rotenburg ou Carcasonne. O tipo de cidade axeitado para este hiperconservacionismo sería a Old City, a vella cidade do casco histórico. Por outra banda, resulta altamente significativo que, en Europa, os grandes centros do medio innovador, as tecnópolis, por dicilo en termos de Manuel Castells, se atopen indisolublemente conectadas coas grandes metrópoles, como o crecente occidental de Londres, o suroeste de París ou, a moita menor escala, o parque tecnolóxico de Madrid, en Tres Cantos, prolongado polo xigantesco polígono industrial de Alcobendas-San Sebastián de los Reyes. En cambio, América, igual que o seu antigo adversario, a vella Unión Soviética, coa cidade das estrelas ou Akademgorod, tende a separar as tecnópoles das grandes cidades, a non ser que estas se converteran en dispersas conurbacións, como no caso de Los Ángeles, disolvida sen solución de continuidade por un Ballungszentrum que ocupa todo o sur da Alta California, cinguida por aglomeracións tecnocientíficas como Silicon Valley, Orange County, Santa Mónica, etc.

Desde logo, esta confrontación entre a dispersión entre a natureza, pero con características habitacionais comúns, dun lado, e o arraigamento na Terra, mediante unha lenta e continua sedimentación de estilos e modos de vida distintos, do outro lado, van paulatinamente segregando, por así dicilo, dous ideais ben distintos do que significa ser home e, por conseguinte, habitar no mundo. E non teño dúbidas de que $o$ american way of life, ou mellor, way of dwelling, corresponde con maior rigor ao neohumanismo xa citado que ao neohistoricis- 
mo europeo. Un neohumanismo fortemente contraditorio, composto de individuos tan narcisistas psiquicamente como intercambiables desde un punto de vista mercantil, tan autárquicos como sometidos a un mesmo cuño mediático, tan desexosos dunha estética contemplación da natureza como plenamente desarraigados da terra natal -diso que os alemáns chaman Heimat-, tan sobrados de técnicas como faltos de mitos e de historias.

E, así e todo, esas características deron o seu froito a partir das sementes que pensadores e artistas europeos levaron a América. En efecto, Mépolis, a non cidade actual (singulare tantum) repartida e distribuída en mil versións, todas elas semellantes, polo vasto subcontinente americano, ten os seus ancestros nunha dobre obsesión: a pureza xeométrica dos sólidos regulares e a veneración da máquina. Os dous trazos, non en van produto dos dous grandes renacementos do humanismo: o artístico italiano do Quatrocento e o tecnocientífico anglosaxón do século XIX. E ambos os dous son debidos, ao meu ver, a un dobre terror antitético: o terror ao imprevisible da terra, sempre susceptible de producir monstros, orográficos e animais, dunha banda; e, da outra banda, paradoxalmente, ao carácter indefinido e ilimitado do espazo e mais do tempo, unha vez desenganchados eses ámbitos da catena aurea entium que os vinculaba a unha divindade providencial e calculadora. Cómpre, xa que logo, recortar, configurar esa amorfa infinidade, para evitar que nela aparezan, pois todo pode aparecer no isotrópico e na tediosa sucesión irreversible, eses pavorosos ou ridículos luxus naturae propios dunha desenfreada e luxuriosa Mater Genitrix.

Nada máis instrutivo, ao respecto, que a fantástica, perfecta città ideale bosquexada na escola de Piero della Francesca e conservada en Urbino. A impresionante táboa mostra unha serie de habitáculos de forte carácter xeométrico, rectilíneo, dentro dunha perspectiva dominada polo ollo solar do artista. E nada máis inquietante que o feito de que nesta sosegada veduta, na que triunfa o ideal humanista, estean ausentes os homes. Como se dunha escenografía en que se levantou o pano de fondo demasiado pronto se tratase, esa cidade está baleira. Toda historia, da cidade ou dos seus habitantes, foi eliminada deste conxunto de seca e inconmensurable pureza. A cidade do home, resulta cando menos habitable polos homes?

Apenas dous séculos máis tarde, o enxeñeiro e matemático René Descartes, o grande instaurador da Filosofía moderna, ratificará a estreitísima semellanza 
entre a construción da cidade e a planificación do pensamento. En ambos os dous casos, cómpre eliminar os detritus, os superstites da historia e das historias. No canto das estreitas canellas, dos vicoli, resultados da interacción entre as dispoñibilidades do chan, o crecemento das familias e a necesidade de protección da intemperie, a nova filosofía e o novo urbanismo coinciden na mirada panóptica do artista-proxectista. Todo ha de ser recto, claro e distinto. Todo, sometido á mente matemática. E, logo, á máquina. No novo humanismo das vangardas co que o século XIX se transvasa no primeiro terzo do XX, a consigna cartesiana transmutouse xa nunha perfecta simbiose entre a máquina e a arte.

Palabra de Theo van Doesburg, do moi purista, e ata místico, movemento De Stijl: «Toda máquina é a espiritualización dun organismo [...]. A máquina é, por excelencia, un caso de disciplina espiritual [...]. A nova sensibilidade artística do século XX non se limitou a sentir a beleza da máquina, senón que tomou tamén coñecemento das súas infinitas posibilidades expresivas para as artes». Xeometría a través da mecanización significa xa, para von Doesburg, espiritualización. A máquina é fermosa porque permite a expresión... De que, senón da mente e a man humanas, pero xa metamorfoseadas, xa harmónica, ritmicamente pausadas e pautadas pola máquina? $\mathrm{O}$ que se expresa é, positivamente, a simbiose; negativamente, o expresado é a expulsión, o moi paradoxal desterro de canto sabe $\mathrm{e}$ cheira a terra. Aedificare di, agora, plenamente a súa verdade: construír unha sede, un asentamento contra iso que Camus, entre temeroso e frívolo, musitaba en La chute: "Xa sabe: a vida e os seus crimes».

Un paso máis, e atopamos o credo específico da arquitectura como humanismo en Hans Hollein. Para el, a edificación é unha autoafirmación espiritual. Como se dun manexo hábil da hegeliana «astucia da razón» se tratase, Hollein sinala que a arquitectura tende á dominación do espazo dado, ese contraditorio quantum infinito dado que atormentaba ao bo Kant, mediante a construción artificial de espazos. Por iso, despegándose aparentemente do humanismo clásico só para mergullarse no humanismo tecnocientífico, Hollein declara que en arquitectura resulta inútil facer cuestión da beleza mimética, figurativa, e en todo caso improcedente cifrar o seu empeño na forma e a proporción. O que a arquitectura ofrece é máis ben «unha beleza sensual de forza elemental». $\mathrm{O}$ último termo, elemental, podería facernos pensar nun recoñecemento do espesor 
telúrico, en última instancia sempre indómito, co que cómpre contar no momento dos Grundrisse, dos trazos básicos do plano arquitectónico, e máis aínda da súa realización fáctica. Pero, no canto diso, Hollein sorprende cunha confesión de hipercartesianismo: o elemental, o simple, é produto do home contra a terra. Velaquí o canto puro do arquitecto humanista: "A arquitectura non pretende obxectivos. Xa acabará por atopar a súa utilidade aquilo que nós construímos. A forma non segue á función, contra o lamarckismo en xeral, e o funcionalismo en particular. A forma non xorde do seu propio acorde. A gran decisión do home cífrase en construír un edificio como un cubo, como unha pirámide ou como unha esfera».

A que se debe esta predilección, tan clásica, tan humanista, polos sólidos regulares, e especialmente pola esfera, como se mostra en figuras tan senlleiras, e visionarias, como Ledoux ou Boullée, o arquitecto da Revolución Francesa? A resposta é obvia: porque tal é o modo humano de desafiar a gravidade, carga natural das cousas. Neste sentido, o arquitecto sería un servidor do espírito. Mais dun espírito humano, demasiado humano, e que nos nosos días -como dixemos antes- se transformou nun espectro: na pantasma do humanismo.

Non resulta difícil pasarlle revista aos trazos xerais dunha arquitectura de inspiración neohumanista. Para iso, elixirei un exemplo asiático e tres europeos, pero claramente contaxiado da doutrina que acabará por triunfar en América:

1) Minimización das diferenzas naturais entre arriba e abaixo, en estreito paralelismo co minimalismo en escultura. Un exemplo paradigmático desta perfección puramente estrutural, na que o ceo e mais a terra deixan de ter outro sentido que o de ser límites inanes, perforados na súa xa inútil negrura, da base e altura do edificio, sería o contido nas torres ata o de agora máis altas do planeta: as Torres Petronas de Kuala Lumpur, oscilantes entre unha Torre de Babel por duplicado e dous rutilantes foguetes xemelgos de Cabo Cañaveral -o que vén sendo a mesma cousa- e erguidas na enigmática e exótica Malaisia, segundo rezan os anuncios turísticos das axencias de viaxe.

2) Estabilidade plena, acabado do edificio en e para si, superando as formas naturais, inextricablemente entrelazadas unhas coas outras. Ideal da imaxe pura kantiana, na que figura e forma, schéma e morphé se copertencen en virtude da regra de construción, da definición xenética da estrutura, substituín- 
do así a physis grega, expulsada do atelier do arquitecto-artista por obsoleta... e incontrolable. Un bo e fermoso exemplo sería o do proxecto para o Centro Cultural de Copenhague, de Christian de Portzamparc (1993).

3) Falta, ad limitem, absoluta de contextualización: o edificio tende a separarse de toda relación coa paisaxe ou a historia. Como antes se dixo, é o soño da cousa illada, magnífica na súa autonomía: mente concipio, dicía Galileo. Tales son as sobrias e ciclópeas estruturas de Carlo Aymonino e de Aldo Rossi, que se impoñen sobre a paisaxe. Máis aínda, que cancelan toda paisaxe. Triunfo do home, do construtor e ordenador, sobre a Terra. A «absolutización» da xeometría, a medida da terra, acaba por facer que se esqueza esta.

4) Por fin, os edificios que obedecen, tácita ou conscientemente, os ditados humanistas tenden a mostrar, en paradoxal conflito coa estabilidade propia da arquitectura, un carácter esencialmente móbil, é dicir, que están compostos de elementos montables e reformulables ad libitum, como propugna o propio Van Doesburg en Cara a unha arquitectura plástica. Por exemplo, un conxunto de ocos poliedros regulares, travesamente colocados en inestable equilibrio, como lúdica metáfora dos sinais de tráfico. Signos luminosos. Mobilidade simbólica establecida para regular a mobilidade real, viaria, na rotonda de entrada á Baía de Cardiff, unha típica mostra de site specific art, obra de Pierre Vivant (1992).

É posible, ou mesmo desexable, loitar contra este neohumanismo de tan claro sabor americano? Que sucede cando, por unha banda, a paisaxe é xa cordilleira arquitectónica -alén da sobriedade de Rossi, pénsese, por exemplo, no cerco babélico do Central Park de Nova York-, ou cando a cidade celebra a súa propia codificación urbana: como suprema exaltación do tráfico, alí onde todo tránsito ten o seu paradoxal asento? Xorde, daquela, a pregunta inescusable, mais sempre preterida: que nos acontece, daquela, coa terra?, que lle sucede á terra con nós, os homes chegados talvez demasiado tarde para sentir o latexo da Terra e para serlle fieis ao seu sentido?

Un dos arquitectos máis sensibles a esta chamada da Terra introduciuse silandeira, delicadamente, nunha espléndida paisaxe natural suíza, xerando desde e contra o penedo mesmo unhas termas de muros esburacados -homenaxe panteísta á igrexa de Ronchamp, de Le Corbusier. Aquí, os muros deixan ser, permítenlle respirar á terra e conséntenlle facer acto de presenza no van mesmo. 
E iso, utilizando materiais extraídos da propia montaña, remansando as augas, facendo que as rochas se reflictan nelas. E así e todo, mesmo nesta espléndida mostra de exposición de terra, está agochada, baixo o mito do retorno á orixe pura, a hybris humanista. Pois se Zumthor anhela unha volta, imposible, á natureza virxe -polo tanto, non á terra como o fusco retráctil, senón como o aínda non pisado... para que estea dispoñible para a súa utilización polo home!-, é porque pensa, ou soña, que esa abnegada e desprendida natureza podería sandar os corpos humanos, con tal de que se lle permitise volver ser como antes, cando todo existía por primeira vez: «a confrontación coas características de entidades concretas como a montaña, a pedra, a auga, no fondo dunha precisa tarefa construtiva, implica a posibilidade de captar, de extraer unha parte da esencia orixinaria e, por así dicilo, inviolada pola civilización destes elementos, e de madurar unha arquitectura que parte das cousas e retorna a elas» (Zumthoor, 1991, p. 29).

Así pois, Zumthor afirma que el non quere violar a natureza, como faría a civilización, e, non obstante, pretende extraer nada menos que a súa esencia orixinaria para poñela ao servizo dos homes! Aquí, esta neorousseauniana fantasía à la New Age coincide co neotomismo dun Romano Guardini, consumido na «sede por participar da fonte primitiva do ser». Deus sive Natura. Que importa se o sive oculta o home, aquel para o que é igual unha cousa ou a outra? $\mathrm{O}$ que Zumthor esquece é que xa, de sempre e por adiantado, é demasiado tarde... para a natureza, e para o ser. Que a maduración non é da arquitectura, senón da Terra, que dá e quita sazón e tempo alto, mentres que o ser do home, en canto estación do instante, só construíndo lle dá espazo-de-tempo ao tempo das cousas, antes de que o seu propio tempo expire. Mais non en balde, se a súa obra poeticamente fai habitable a Terra. Que esta, a Terra, só se dá no abrazo mortal do desterrado Dasein.

«Aber Freund! Wir kommen zu spät» (Pero, amigo! Chegamos demasiado tarde). Así apostrofa Hölderlin ao su revolucionario amigo Wilhelm Heinse, ao comezo da sexta estrofa de Pan e viño. Chegamos, en efecto, demasiado tarde para o ceo, para os deuses. Mais non, talvez, malia os esforzos humanistas, para a Terra. Por iso somos mortais. Por iso existimos construíndo hábitats do intervalo. Hábitats da sazón e do desacougo. Da maduración da vida, estando á morte. Tal é o arché: pórtico vibrante. Tal a transparencia do fondo mesmo. $\mathrm{O}$ 
filósofo sabe dese pensamento mortal. Pois «Philosophieren heisst Existieren aus dem Grunde» (Filosofar quere dicir existir desde o fondo) (Heidegger, 1990, p. 285).

Ten a arquitectura a brillante, e ás veces vacua, configuración actual das nosas cidades oídos que atenden o xordo murmurio dese traballado fondo, ou seguiremos oscilando entre o utilitarismo e o ornamento, entre o técnico e o lúdico, ad majorem hominis gloriam? E así e todo, ao cabo, só se trataría -nada menos- de prestarlle atención a algo mínimo, a algo que, a través de Séneca (Epistula XVII), non deixa de solicitarnos ela, a natureza mesma. Pois natura minimum petit. Por esa nimiedade, por esa fisura mínima estase a gretar a estólida figura do neohumanismo. Será posible, a este respecto, chegar a tocar fondo algún día? Tanto na súa obra La questione della cosa como en Contribuciones a la filosofia, Martin Heidegger legounos entre outras moitas cousas unha ensinanza que me parece altamente relevante, a saber: "que proxección é retroferencia», que cómpre saber dar un paso atrás para botar algunha luz sobre o inmediato futuro, dilucidando a obra de pensadores, poetas ou artistas xa sidos, si (die Gewesene), mais non cubertos polo po do pasado, senón «advenideiros» (die Zu-künftigen, como lles chama Heidegger) precisamente por ter esencialmente sido, é dicir, saber escoitar os rumores de fondo dos tempos. E así como o pensador escolleu para o seu tempo - un tempo sombrío e terrible, unha lama onde el mesmo choupou, entre a inxenuidade do Herr Professor e a ambición do Führer-Philosoph- as figuras de Hölderlin e Nietzsche, e despois as de Trakl ou Cézanne, así tamén nós poderiamos escoller para este noso tempo, oscilante entre a banalidade propia e o pavor ao estraño, dúas figuras exemplares, tamén na súa ambigüidade, primeiro, e logo na súa entrega apaixonada á resistencia da Terra, conxuntando man e mirada: Martin Heidegger e Mies van der Rohe, dedicados ambos os dous, pensador e arquitecto, ao seu modo e maneira, a facer habitable a Terra. Deste modo, talvez poidamos agardar con serenidade, sen espaventos e sen nos facer ilusións, un tempo que saiba escoitar o adagio senequista e o enlace naturalmente cun Ring, cun filosófico anel cansado de trompetas pseudowagnerianas, coidadoso en cambio do florecer das humildes cousas e lugares e cunha transparencia arquitectónica que deixe ver o fondo en canto fondo. 


\section{BibliografíA}

DuQue, F.: En torno al humanismo. Heidegger, Gadamer, Sloterdijk, Madrid, Tecnos, 2002.

DuQue, F.: Contra el humanismo, Madrid, Abada, 2003.

Ferguson, N.: Colossus: The Price of America's Empire, Nova York, Penguin, 2004.

HeIDEGGER, M.: Metaphysische Anfangsgründe der Logik im Ausgang von Leibniz (SS 1928); Gesamtausgabe, Frankfurt, Klostermann, 1990.

Zumthor, P.: «Il nocciolo duro della bellezza», en L. MÜller: Pensare Architettura, Zúric, 1997, p. 29. 